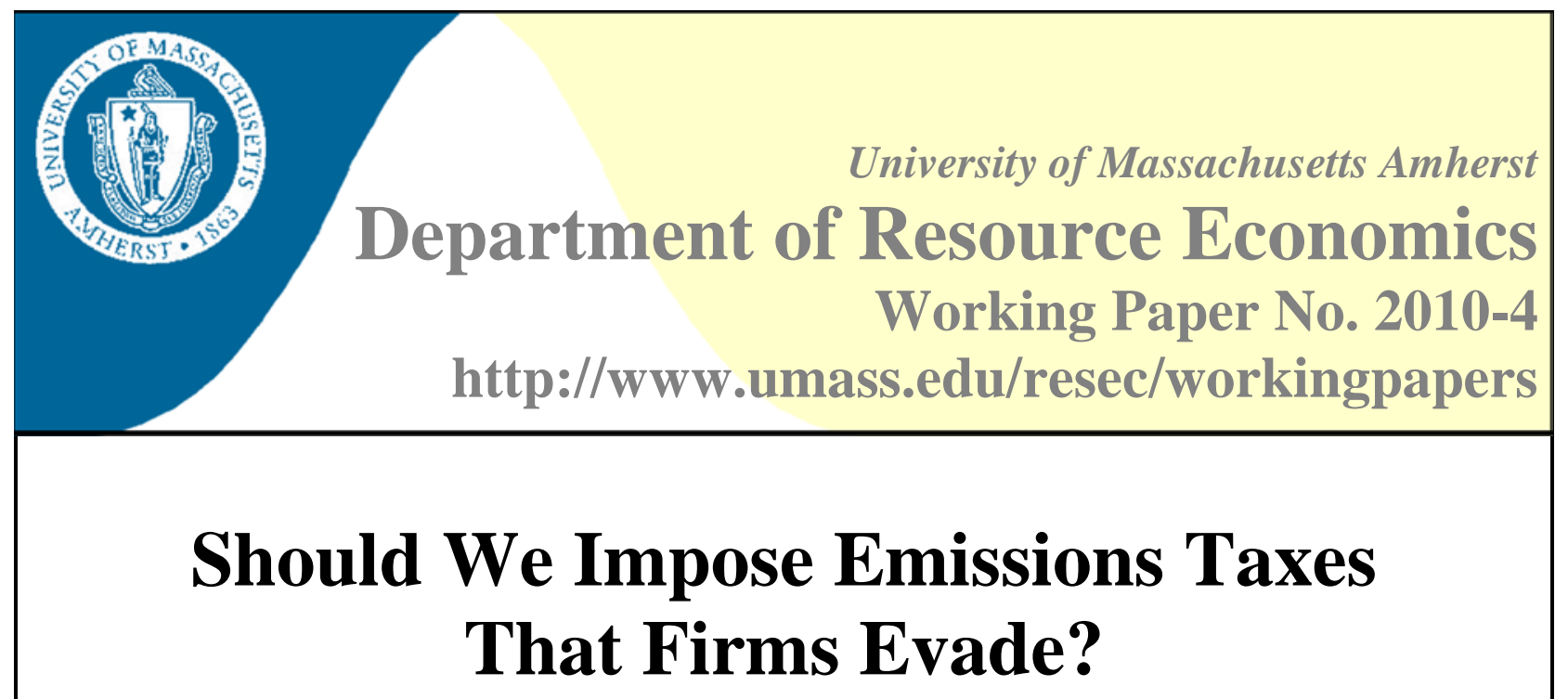

John K. Stranlund ${ }^{1}$

\begin{abstract}
:
Most of the theoretical literature on enforcing environmental policies focuses on situations in which pollution sources are noncompliant. However, some recent work suggests that these situations will very often involve suboptimal policy designs. Thus, the circumstances under which it is efficient to implement policies that do not motivate full compliance appear to be more limited than most of the literature would imply. In this paper, I identify several circumstances under which regulators may conserve enforcement costs by implementing emissions taxes that firms evade. I demonstrate that a regulator can use a firm's tax evasion to reduce monitoring effort, but only if its monitoring strategy can be made an increasing function of the firm's emissions, if the probability of sanctioning a violation is increasing in the size of the violation, or if the firm's manager is risk averse. Whether an optimal tax/enforcement policy should allow noncompliance under these circumstances depends on the value of reduced monitoring effort set against the increase in expected sanctioning costs, and the costs of dealing with the added regulatory uncertainty that is produced by imperfect compliance.
\end{abstract}

Keywords: compliance, enforcement, emissions taxes, monitoring, sanctions, uncertainty

JEL Classification: L51, Q58

\footnotetext{
${ }^{1}$ John K. Stranlund, Department of Resource Economics University of Massachusetts, 214 Stockbridge Hall 80 Campus Center Way, Amherst, MA 01003-9246

E: stranlund@resecon.umass.edu P: 413-545-6328 F: 413-545-5853
} 


\title{
Should we impose emissions taxes that firms evade?
}

\author{
JOHN K. STRANLUND \\ Department of Resource Economics \\ University of Massachusetts-Amherst
}

\begin{abstract}
Most of the theoretical literature on enforcing environmental policies focuses on situations in which pollution sources are noncompliant. However, some recent work suggests that these situations will very often involve suboptimal policy designs. Thus, the circumstances under which it is efficient to implement policies that do not motivate full compliance appear to be more limited than most of the literature would imply. In this paper, I identify several circumstances under which regulators may conserve enforcement costs by implementing emissions taxes that firms evade. I demonstrate that a regulator can use a firm's tax evasion to reduce monitoring effort, but only if its monitoring strategy can be made an increasing function of the firm's emissions, if the probability of sanctioning a violation is increasing in the size of the violation, or if the firm's manager is risk averse. Whether an optimal tax/enforcement policy should allow noncompliance under these circumstances depends on the value of reduced monitoring effort set against the increase in expected sanctioning costs, and the costs of dealing with the added regulatory uncertainty that is produced by imperfect compliance.
\end{abstract}

Keywords: Compliance, Enforcement, Emissions Taxes, Monitoring, Sanctions, Uncertainty JEL Codes: L51, Q58.

Correspondence: John K. Stranlund, Department of Resource Economics, 214 Stockbridge Hall, 80 Campus Center Way, University of Massachusetts-Amherst, Amherst, MA 01003, USA. Phone: (413) 545-6328, Fax: (413) 545-5853, E-mail: stranlund@resecon.umass.edu.

Acknowledgement: Carmen Arguedas and Carlos Chavez provided valuable comments on earlier drafts of this paper. 


\section{Should we impose emissions taxes that firms evade?}

\section{Introduction}

By far the most common approach in the theoretical literature on the problem of enforcing environmental policies is to assume that regulators do not or cannot apply enough enforcement pressure to induce compliance by sources of pollution. Examples of this approach in the literature on the enforcement problem for emissions taxes include Harford (1978 and 1987), Sandmo (2002), Montero (2002), Cremer and Gahvari (2002), and Macho-Stadler and PerezCastrillo (2006). This approach is also common in the literature concerning emissions trading, including in Malik (1990), Keeler (1991), van Egteren and Weber (1996), and Stranlund and Dhanda (1999). Since analysts usually assume that firms will be noncompliant, the question of whether it is efficient to design environmental regulations with the expectation that firms will be noncompliant is rarely addressed.

However, some recent work questions the social value of designing environmental regulations that allow noncompliance. Stranlund (2007) considers the joint determination of an emissions trading program and its enforcement in the cost-effective achievement of an aggregate emissions standard. He demonstrates that when regulators are fully informed about firms’ abatement costs, to reach an exogenous aggregate target the optimal policy calls for inducing full compliance. Under incomplete information about firm's abatement costs, the full-compliance result continues to hold if a constant marginal penalty for violations is a constant multiple of the price of emissions permits. Arguedas (2008) comes to the same full-compliance conclusion about the efficient design of an emissions standard for a single firm. Stranlund, Chavez, and Villena (2009) examine efficient emissions taxes and their enforcement and conclude that 
inducing full compliance is optimal, except possibly when monitoring can be based on observable correlates of firms' emissions. ${ }^{1}$

These recent papers suggest that the focus on noncompliance in the literature often involves analyzing suboptimal policy designs. Consequently, instead of starting from the assumption that environmental policies should not or cannot be designed so that regulated firms are compliant, perhaps our first inclination should be to start from inducing full compliance and then look for ways to improve on this result.

That is the approach taken in this paper. A simple, yet effective, strategy for enforcing an emissions tax is to monitor firms in a way that produces a constant probability of detecting a firm's noncompliance and to set a constant unit penalty for evaded taxes so that the resulting expected marginal penalty is equal to the firm's emissions tax. Under the assumption that firms comply when they are indifferent between compliance and noncompliance, this strategy induces a firm's full compliance. This enforcement strategy is valuable because it does not require hardto-obtain information about individual firms for implementation and it eliminates the expected costs of penalizing firms.

For a single firm, I compare this simple enforcement strategy to a more complicated strategy that, together with a jointly determined tax, is designed to achieve the same level of emissions from the firm. The more complex strategy allows a regulator to make the probability of detecting and punishing a noncompliant firm dependent on the firm’s emissions and emissions report, and to apply sanctions according to a strictly convex penalty function. Examples of

\footnotetext{
${ }^{1}$ The full-compliance results of Stranlund (2007), Arguedas (2008), and Stranlund et al. (2009) depend on the assumption that imposing sanctions is costly. In fact, this is the main reason for designing policies that achieve full compliance. Despite the reasonableness of assuming costly sanctions, it is not common in the literature on enforcing environmental policies. All of the works cited in the first paragraph of this introduction assume that sanctions are imposed without cost.
} 
enforcement strategies for taxes that include some or all of these features include those modeled by Harford (1978 and 1987), Sandmo (2002), Cremer and Gahvari (2002), and Macho-Stadler and Perez-Castrillo (2006), among others. Recall that these authors focused on outcomes in which firms do not comply fully with an emissions tax. The central question of this study is whether designing such an enforcement strategy so that a firm is expected to be noncompliant can be cheaper than inducing the firm's full compliance with a constant expected marginal penalty.

The focus on inducing the same level of emissions with alternative tax/enforcement policies stems from the desire to look for policies that minimize the enforcement costs of achieving a given environmental outcome. Knowledge about how to induce an arbitrary level of emissions with minimum expected enforcement costs can ultimately be fed into the problem of inducing optimal emissions with an emissions tax. The focus in this paper on a single firm is a simplifying assumption. However, applying the results from the model of one firm to the control of a pollutant emitted by multiple firms is justified as long as a regulator can design a policy of firm-specific taxes and their enforcement, and if aggregate abatement costs, monitoring costs, and sanctioning costs are separable in individual abatement, monitoring, and sanctioning costs.

The approach of this paper is similar to the approach taken in Stranlund et al. (2009), but two important features are included that they did not consider. First they assume that firms are risk neutral, while the manager of a firm in this paper may be risk averse. Not only is this a reasonable extension, it also allows us to consider whether risk aversion can be exploited to conserve enforcement costs. Second, sanctioning may be imperfect in the sense that a firm that is found evading a part of its tax liability faces a probability of being sanctioned for this violation that is separate from the probability that the violation is discovered. This may occur if a violation 
is referred to a court for prosecution and the outcome of the court proceedings is uncertain. Most of the authors in the related literature assume that a sanction is imposed with certainty if a violation is discovered, although (Harford (1978 and 1987) combines the probabilities of detecting a violation and sanctioning it into one probability. Uncertainty about whether a discovered violation will be punished weakens deterrence because it reduces the probability that a noncompliant firm will be sanctioned. Explicitly modeling the uncertainty of sanctioning discovered violations is a worthwhile extension of existing models because it is an important real-world phenomenon, and because uncertain sanctions may provide a justification for designing enforcement strategies that do not induce full compliance.

The rest of the paper proceeds as follows. After presenting a model of a firm's optimal choices under an emissions tax in the next section, and showing what is required to induce the firm's compliance with a constant expected marginal penalty in section 3 , the main results of this work are presented in section 4. There it is shown that if a regulator's goal is to induce the firm's compliance, then it cannot reduce its monitoring effort below what is required to induce compliance with a constant expected marginal penalty. Thus, conditioning its monitoring effort on correlates of the firm's emissions or its emissions report is not useful. Similarly a strictly convex penalty is not useful. Moreover, the regulator cannot exploit a firm's risk aversion to reduce monitoring effort. However, there are conditions under which a regulator can use the firm's noncompliance to reduce its monitoring effort—it can do so if its monitoring strategy can be conditioned on observable correlates of the firm's emissions, if the probability of sanctioning the firm's violation is increasing in the size of the violation, or if the firm's manager is risk averse. 
Section 5 of the paper contains an extended discussion of whether emissions tax policies should be designed so that firms are compliant, or whether they should be designed with the expectation that they will attempt to evade some part of their tax liabilities. Implementing an emissions tax with an enforcement strategy that motivates full compliance does not depend on any information about individual firms, and it eliminates the costs and uncertainty associated with sanctioning noncompliant firms. However, the results of this paper suggest that there are limited circumstances under which monitoring effort can be reduced with a more complex enforcement strategy that allows firms to be noncompliant. Whether it is optimal to implement a tax that firms evade depends on the benefit of lower monitoring effort, set against the increased costs of sanctioning noncompliant firms and the regulatory view of having to deal with the increased uncertainty and additional information requirements associated with allowing noncompliance. In all cases it is simpler to implement an enforcement strategy that motivates full compliance. In many cases this will be efficient as well.

\section{A model of compliance with an emissions tax}

The analysis of this paper is based on the control of the emissions of a single firm with an emissions tax. The firm's emissions are denoted $q$, and the firm's gross profit in terms of emissions is $b(q)$, which is strictly concave. Absent an inducement to control its emissions, the amount of pollution the firm releases is the solution to $b^{\prime}(q)=0$. Denote this value of $q$ as $q^{0}$, and let us limit the analysis to emissions less than $q^{0}$. For $q<q^{0}, b^{\prime}(q)>0$. One can interpret $b^{\prime}(q)$ as the firm's marginal abatement costs, because it reveals the firm's reduction in profit from reducing its emissions by one unit. 
The firm is required to submit a report of its emissions $r$, which are taxed at rate $t$. The firm complies with the tax if it reports its true emission $(r=q)$, but it is noncompliant if it attempts to evade some part of its tax liability by reporting $r<q$. The regulator cannot determine the firm’s compliance status without a costly audit. Like Harford (1978 and 1987), Sandmo (2002) and others, let us allow for the possibility that the regulator can base the probability of an audit on observable correlates of the firm's emissions as well as on the firm's emissions report. We do not model the observable variables that the firm's emissions produce, choosing instead to simply let $\pi(q, r)$ be the probability that the regulator audits the firm.

Moreover, we do not model the cost of monitoring the firm explicitly. However, we assume that monitoring cost is strictly increasing in $\pi$. The audit probability is endogenous in this work.

In contrast, the probability that a discovered violation is punished is exogenous. If the regulator finds the firm is in violation it may have to bring the case to a court for prosecution, the outcome of which is uncertain. However, assume that a greater violation increases the probability that the court will sanction the firm. Thus, let the probability of sanctioning the firm if it is found to be noncompliant be $\rho(q-r)$ with $\rho^{\prime}(q-r)>0$. The probability the firm will be sanctioned if it is noncompliant is the probability that it is audited times the probability that a court will apply the sanction, which is denoted $m(q, r)=\pi(q, r) \rho(q-r)$. The sanction applied to the firm's violation is the increasing and convex (perhaps weakly convex) penalty function $f(q-r)$. Like the cost of monitoring the firm, we do not model sanctioning costs explicitly. We do, however, assume that they are strictly positive. Sanctioning costs may depend on a firm’s violation and its penalty, but the results of this paper do not depend on specifying these relationships. 
The manager of the firm is risk neutral or risk averse, and therefore has a concave (perhaps weakly concave) utility function $u$. The manager's expected utility under the tax/enforcement policy $[t, \pi(q, r), f(q-r)]$ is

$$
U(w)=(1-\pi \rho) u\left(w^{0}\right)+\pi\left[(1-\rho) u\left(w^{0}\right)+\rho u\left(w^{1}\right)\right]=(1-m) u\left(w^{0}\right)+m u\left(w^{1}\right),
$$

where

$$
w^{0}=b(q)-t r
$$

and

$$
w^{1}=b(q)-t r-f(q-r)
$$

Substitute [2] and [3] into [1] to obtain

$$
U(q, r)=(1-m) u(b(q)-t r)+m u(b(q)-t r-f(q-r)) .
$$

(Often the arguments of certain functions are suppressed to conserve notation; e.g., $m=m(q, r)$ ). Assuming that the manager of the firm chooses strictly positive emissions and emissions report, it maximizes $U(q, r)$ subject to $q-r \geq 0$. Let $\mathcal{L}$ denote the Lagrange equation for the manager's problem and let $\lambda$ be the multiplier attached to the constraint $q-r \geq 0$. Assume throughout that $U(q, r)$ is strictly concave so that the following Kuhn-Tucker conditions are both necessary and sufficient to identify the firm's optimal choices of emissions and emissions report:

$$
\begin{aligned}
\mathcal{L}_{q} & =(1-m) u^{\prime}\left(w^{0}\right) b^{\prime}(q)-m_{q} u\left(w^{0}\right)+m u^{\prime}\left(w^{1}\right)\left(b^{\prime}(q)-f^{\prime}(q-r)\right)+m_{q} u\left(w^{1}\right)+\lambda \\
& =b^{\prime}(q)\left[(1-m) u^{\prime}\left(w^{0}\right)+m u^{\prime}\left(w^{1}\right)\right]-m_{q}\left[u\left(w^{0}\right)-u\left(w^{1}\right)\right]-m u^{\prime}\left(w^{1}\right) f^{\prime}(q-r)+\lambda=0 ; \\
\mathcal{L}_{r} & =-t(1-m) u^{\prime}\left(w^{0}\right)-m_{r} u\left(w^{0}\right)+m u^{\prime}\left(w^{1}\right)\left(-t+f^{\prime}(q-r)\right)+m_{r} u\left(w^{1}\right)-\lambda \\
& =-t\left[(1-m) u^{\prime}\left(w^{0}\right)+m u^{\prime}\left(w^{1}\right)\right]-m_{r}\left[u\left(w^{0}\right)-u\left(w^{1}\right)\right]+m u^{\prime}\left(w^{1}\right) f^{\prime}(q-r)-\lambda=0 ; \\
\mathcal{L}_{\lambda} & =q-r \geq 0, \lambda \geq 0, \lambda(q-r)=0 .
\end{aligned}
$$




\section{A simple enforcement strategy for inducing compliance}

The analytical approach of this paper is to compare the monitoring under the enforcement strategy of the model developed thus far to monitoring under a very simple strategy that features a constant expected marginal penalty that induces the firm's compliance. A constant expected marginal penalty requires that the probability the firm is audited is independent of its emissions and emissions report and that the marginal penalty is a constant. The following lemma specifies the minimal monitoring required to induce the firm's compliance under such an enforcement strategy, along with the firm's emissions when the regulator follows this strategy.

Lemma 1: Under a constant audit probability $\pi$, and a constant unit fine for evaded taxes $\phi$ that satisfies $t \leq \rho(0) \phi$ :

(1) The firm is compliant if and only if $t \leq \pi \rho(0) \phi$.

(2) To induce the firm's compliance with minimal monitoring, the regulator chooses its audit probability so that $t=\pi \rho(0) \phi$.

(3) When the firm is compliant it chooses its emissions so that $b^{\prime}(q)=t$.

Proof of Lemma 1: Under a constant $\pi, m=\pi \rho(q-r)$. With this and $\phi=f^{\prime}(q-r)$, [5] and [6] can be written as:

$$
\begin{aligned}
& \mathcal{L}_{q}=b^{\prime}(q)\left[(1-m) u^{\prime}\left(w^{0}\right)+m u^{\prime}\left(w^{1}\right)\right]-\pi \rho^{\prime}\left[u\left(w^{0}\right)-u\left(w^{1}\right)\right]-m u^{\prime}\left(w^{1}\right) \phi+\lambda=0 ; \\
& \mathcal{L}_{r}=-t\left[(1-m) u^{\prime}\left(w^{0}\right)+m u^{\prime}\left(w^{1}\right)\right]+\pi \rho^{\prime}\left[u\left(w^{0}\right)-u\left(w^{1}\right)\right]+m u^{\prime}\left(w^{1}\right) \phi-\lambda=0 .
\end{aligned}
$$

When the firm is compliant, $w^{0}=w^{1}$ and $m=\pi \rho(0)$. Then, [8] and [9] imply:

$$
b^{\prime}(q)-\pi \rho(0) \phi+\lambda / u^{\prime}\left(w^{0}\right)=0 ;
$$




$$
-t+\pi \rho(0) \phi-\lambda / u^{\prime}\left(w^{0}\right)=0
$$

To prove part (1) of the lemma, rewrite [11] as $t-\pi \rho(0) \phi=-\lambda / u^{\prime}\left(w^{0}\right) \leq 0$. The inequality follows because $\lambda \geq 0$ and $u^{\prime}\left(w^{0}\right)>0$. Thus, the firm is compliant only if $t-\pi \rho(0) \phi \leq 0$. Obviously this requires $t \leq \rho(0) \phi$.

To prove that the firm is compliant if $t \leq \pi \rho(0) \phi$, suppose toward a contradiction that $q-r>0$ when $t \leq \pi \rho(0) \phi$. When the firm is noncompliant, $m=\pi \rho(q-r)$ and $\lambda=0$. Substitute these into [9] and rearrange the result to obtain:

$$
\begin{gathered}
-t\left[(1-\pi \rho(q-r)) u^{\prime}\left(w^{0}\right)+\pi \rho(q-r) u^{\prime}\left(w^{1}\right)\right]+\pi \rho(q-r) \phi u^{\prime}\left(w^{1}\right) \\
+\pi \rho^{\prime}(q-r)\left[u\left(w^{0}\right)-u\left(w^{1}\right)\right]=0 .
\end{gathered}
$$

Note first that $t \leq \pi \rho(0) \phi$ implies $t<\pi \rho(q-r) \phi$ when $q-r>0$. Moreover, since $u$ is concave, $w^{0}>w^{1}$ implies $u^{\prime}\left(w^{1}\right) \geq u^{\prime}\left(w^{0}\right)$. Therefore, because $(1-\pi \rho(q-r)) u^{\prime}\left(w^{0}\right)+\pi \rho(q-r) u^{\prime}\left(w^{1}\right)$ is a linear combination of $u^{\prime}\left(w^{1}\right)$ and $u^{\prime}\left(w^{0}\right)$, it is not greater than $u^{\prime}\left(w^{1}\right)$. This and $t<\pi \rho(q-r) \phi$ imply $-t\left[(1-\pi \rho(q-r)) u^{\prime}\left(w^{0}\right)+\pi \rho(q-r) u^{\prime}\left(w^{1}\right)\right]+\pi \rho(q-r) \phi u^{\prime}\left(w^{1}\right) \geq 0$.

Moreover, $\pi \rho^{\prime}(q-r)\left[u\left(w^{0}\right)-u\left(w^{1}\right)\right]>0$ because $w^{0}>w^{1}$ and $\rho^{\prime}(q-r)>0$. Since the left side of [12] is strictly greater than zero, we have a contradiction. Thus, the firm is compliant if $t \leq \pi \rho(0) \phi$

Part (2) of the lemma follows directly from part (1). Combine [10] and [11] to obtain $b^{\prime}(q)=t$, which proves part (3). This completes the proof.

From here on denote a tax/enforcement strategy that induces the firm’s compliance with a constant expected marginal penalty as $\left[t^{c}, \pi^{c}, \phi(q-r)\right]$, where $\pi^{c}$ and $\phi$ are constants and $\phi$ is 
high enough so that $t^{c} \leq \rho(0) \phi$. Lemma 1 reveals that the tax, monitoring, and the unit penalty must satisfy $t^{c}=\pi^{c} \rho(0) \phi$. That is, to induce full compliance with minimal monitoring, the expected penalty of a slight violation must be equal to the tax. Note how the probability of sanctioning a noncompliant firm, $\rho$, weakens the deterrence effects of monitoring and the penalty function. Monitoring must be higher to keep the firm from gambling with the uncertainty of the application of a sanction. It is clear from the perspective of providing deterrence while conserving enforcement resources that it is more efficient to design policies that include clearly stated automatic sanctions, than to make penalties and their application uncertain by, for example, having a court decide how to deal with violators on a case-by-case basis.

Even when sanctions are uncertain, there are several benefits of enforcing an emissions tax so that firms are compliant. First, since it motivates a firm's compliance it eliminates sanctioning costs and the uncertainty associated with sanctioning the firm if it is found to be noncompliant. Second, since the monitoring requirement is determined solely by the tax rate, the unit fine, and the sanctioning probability function, it does not require any information about the firm. Information about anything that determines the firm's gross profit function (like inputs and outputs, or abatement and production technologies), or the risk preferences of the firm's manager are not valuable in setting the monitoring strategy.

However, $\left[t^{c}, \pi^{c}, \phi(q-r)\right]$ does not attempt to exploit the risk aversion of the firm's manager; it does not exploit the information provided by the firm's emission report or indirect evidence of the firm's emissions to conserve monitoring effort, nor does it exploit the possibility that monitoring effort can be reduced under a different policy that results in the firm's noncompliance. The next section addresses whether a regulator can use some or all of these factors to reduce the monitoring effort. 


\section{On the possibility of using a firm's noncompliance to reduce monitoring effort}

We are now ready to compare the monitoring under the simple tax/enforcement policy of the last section, $\left[t^{c}, \pi^{c}, \phi(q-r)\right]$, and the policy, $[t, \pi(q, r), f(q-r)]$, of Section 2. This latter policy allows the regulator to condition its monitoring strategy on observable correlates of the firm's emissions and the firm's emissions report. Moreover, the policy has a penalty function that may be strictly convex. Finally, the policy may motivate the firm to be noncompliant.

For this comparison, we put the two policies on equal footing by holding two items constant. First, both policies induce the same level of emissions from the firm. Note that holding the firm's emissions constant may require the policies to have different tax rates. ${ }^{2}$ Second, so the results do not depend on arbitrary differences in marginal penalties, the equilibrium marginal penalties under $\left[t^{c}, \pi^{c}, \phi(q-r)\right]$ and $[t, \pi(q, r), f(q-r)]$ will be set to the same level. The following lemma is an exact statement of how $\pi^{c}$ and $\pi(q, r)$ compare.

Lemma 2: Consider two policies, both of which include a tax rate, a monitoring strategy, and a penalty function. The first of these policies, $\left[t^{c}, \pi^{c}, \phi(q-r)\right]$, involves a constant monitoring probability and unit penalty chosen so that the firm is compliant. The second policy, $[t, \pi(q, r), f(q-r)]$, features a non-constant monitoring probability and a potentially non-linear penalty function that may result in the firm's noncompliance. If these two policies induce the same level of emissions from the firm and involve the same marginal penalty in equilibrium, monitoring under the two policies are related to each other by

\footnotetext{
${ }^{2}$ The tax rate is the same under both policies if $\pi(q, r)=\pi(q-r)$ under $[t, \pi(q, r), f(q-r)]$, because then $b^{\prime}(q)=t$ under both policies. It is probably not important to consider this possibility because implementing $\pi(q, r)=\pi(q-r)$ would require information on the firm's violation before it is audited.
} 


$$
\begin{gathered}
\pi^{c}-\pi(q, r)=\pi(q, r)\left\{\frac{\rho(q-r)}{\rho(0)} \frac{u^{\prime}\left(w^{1}\right)}{\left[(1-m) u^{\prime}\left(w^{0}\right)+m u^{\prime}\left(w^{1}\right)\right]}-1\right\} \\
+\frac{m_{q}\left[u\left(w^{0}\right)-u\left(w^{1}\right)\right]-\lambda}{\phi\left[(1-m) u^{\prime}\left(w^{0}\right)+m u^{\prime}\left(w^{1}\right)\right]}
\end{gathered}
$$

where recall that $m=\pi(q, r) \rho(q-r)$.

Proof: Under $[t, \pi(q, r), f(q-r)]$ the firm's choices of emissions and emissions report are determined by [5] and [6]. Combine these equations and rearrange the result to obtain

$$
b^{\prime}(q)=t+\left(m_{q}+m_{r}\right) \frac{u\left(w^{0}\right)-u\left(w^{1}\right)}{(1-m) u^{\prime}\left(w^{0}\right)+m u^{\prime}\left(w^{1}\right)}
$$

Since the firm is compliant under $\left[t^{c}, \pi^{c}, \phi(q-r)\right], b^{\prime}(q)=t^{c}$ from part (3) of Lemma 1. This and [14] reveal that the $t^{c}$ and $t$ that induce the same $q$ are related by

$$
t=t^{c}-\left(m_{q}+m_{r}\right) \frac{u\left(w^{0}\right)-u\left(w^{1}\right)}{(1-m) u^{\prime}\left(w^{0}\right)+m u^{\prime}\left(w^{1}\right)}
$$

Substitute [15] into [6] to obtain:

$$
-t^{c}\left[(1-m) u^{\prime}\left(w^{0}\right)+m u^{\prime}\left(w^{1}\right)\right]+m_{q}\left[u\left(w^{0}\right)-u\left(w^{1}\right)\right]+m u^{\prime}\left(w^{1}\right) f^{\prime}(q-r)-\lambda=0 .
$$

Now substitute $t^{c}=\pi^{c} \rho(0) \phi$ (from part (2) of Lemma 1) and $\phi=f^{\prime}(q-r)$ into [16] and rearrange the result to obtain:

$$
\pi^{c}=\frac{m u^{\prime}\left(w^{1}\right)}{\rho(0)\left[(1-m) u^{\prime}\left(w^{0}\right)+m u^{\prime}\left(w^{1}\right)\right]}+\frac{m_{q}\left[u\left(w^{0}\right)-u\left(w^{1}\right)\right]-\lambda}{\phi\left[(1-m) u^{\prime}\left(w^{0}\right)+m u^{\prime}\left(w^{1}\right)\right]} .
$$

To obtain [13], subtract $\pi(q, r)$ from both sides of [17] and collect terms, noting that $m=\pi(q, r) \rho(q-r)$. The proof is complete. 
Evaluating equation [13] in Lemma 2 allows us to determine how $\pi^{c}$ and $\pi(q, r)$ differ with the compliance decision of the firm under $[t, \pi(q, r), f(q-r)]$.

Proposition: Under the conditions of Lemma 2:

(1) If the firm is compliant under $[t, \pi(q, r), f(q-r)]$, then $\pi^{c} \leq \pi(q, r)$.

(2) If the firm's manager is risk neutral and the firm is noncompliant under $[t, \pi(q, r), f(q-r)]$, then $\pi^{c}>\pi(q, r)$ if at least one of the following is true:

(i) $\rho^{\prime}(q-r)>0, \pi_{q}(q, r) \geq 0$;

(ii) $\rho^{\prime}(q-r) \geq 0, \pi_{q}(q, r)>0$.

(3) If the firm's manager is risk averse and the firm is noncompliant under $[t, \pi(q, r), f(q-r)]$, then $\pi^{c}>\pi(q, r)$ if $\rho^{\prime}(q-r) \geq 0$ and $\pi_{q}(q, r) \geq 0$.

Proof: For part (1) of the Proposition, $w^{1}=w^{0}$ if the firm is compliant. This implies $u^{\prime}\left(w^{1}\right) /\left[(1-m) u^{\prime}\left(w^{0}\right)+m u^{\prime}\left(w^{1}\right)\right]=1$ and $u\left(w^{0}\right)=u\left(w^{1}\right)$. Moreover, $\rho(q-r) / \rho(0)=1$ when the firm is compliant. Make these substitutions in [13] to obtain $\pi^{c}-\pi(q, r)=-\lambda / \phi \leq 0$, which is the desired result.

For parts (2) and (3), since the firm is noncompliant $\lambda=0$. Substitute this and $m_{q}=\pi_{q} \rho+\pi \rho^{\prime}$ into [13] to obtain

$$
\pi^{c}-\pi(q, r)=\pi(q, r)\left\{\frac{\rho(q-r)}{\rho(0)} \frac{u^{\prime}\left(w^{1}\right)}{\left[(1-m) u^{\prime}\left(w^{0}\right)+m u^{\prime}\left(w^{1}\right)\right]}-1\right\}
$$




$$
+\frac{\left(\pi_{q} \rho+\pi \rho^{\prime}\right)\left[u\left(w^{0}\right)-u\left(w^{1}\right)\right]}{\phi\left[(1-m) u^{\prime}\left(w^{0}\right)+m u^{\prime}\left(w^{1}\right)\right]} .
$$

For part (2), risk neutrality implies that $u^{\prime}(w)$ is a constant, which further implies

$u^{\prime}\left(w^{1}\right) /\left[(1-m) u^{\prime}\left(w^{0}\right)+m u^{\prime}\left(w^{1}\right)\right]=1$ and $\left[u\left(w^{0}\right)-u\left(w^{1}\right)\right] /\left[(1-m) u^{\prime}\left(w^{0}\right)+m u^{\prime}\left(w^{1}\right)\right]=q-r$.

Make these substitutions in [18] to obtain:

$$
\pi^{c}-\pi(q, r)=\pi(q, r)\left\{\frac{\rho(q-r)}{\rho(0)}-1\right\}+\left(\pi_{q} \rho+\pi \rho^{\prime}\right)(q-r) .
$$

Note that $\rho(q-r) / \rho(0)>1$ if $\rho^{\prime}(q-r)>0$, but $\rho(q-r) / \rho(0)=1$ if $\rho^{\prime}(q-r)=0$. Thus, if $\rho^{\prime}(q-r)>0$, then $\pi^{c}>\pi(q, r)$ as long as $\pi_{q}(q, r) \geq 0$. Moreover, if $\rho(q-r) / \rho(0)=1$, then $\pi^{c}>\pi(q, r)$ as long as $\pi_{q}(q, r)>0$.

For part (3), if the firm is risk averse and it is noncompliant, then $w^{0}>w^{1}$, and consequently, $u\left(w^{0}\right)>u\left(w^{1}\right)$ and $u^{\prime}\left(w^{0}\right)<u^{\prime}\left(w^{1}\right)$. This last implies $u^{\prime}\left(w^{1}\right) /\left[(1-m) u^{\prime}\left(w^{0}\right)+m u^{\prime}\left(w^{1}\right)\right]>1$. Thus, the first term in the sum on the left side of [18] is

$$
\pi(q, r)\left\{\frac{\rho(q-r)}{\rho(0)} \frac{u^{\prime}\left(w^{1}\right)}{\left[(1-m) u^{\prime}\left(w^{0}\right)+m u^{\prime}\left(w^{1}\right)\right]}-1\right\}>0
$$

if $\rho^{\prime}(q-r) \geq 0$. Moreover, if $\rho^{\prime}(q-r) \geq 0$ and $\pi_{q}(q, r) \geq 0$, then $\pi_{q} \rho+\pi \rho^{\prime} \geq 0$. This and $u\left(w^{0}\right)>u\left(w^{1}\right)$ imply

$$
\frac{\left(\pi_{q} \rho+\pi \rho^{\prime}\right)\left[u\left(w^{0}\right)-u\left(w^{1}\right)\right]}{\phi\left[(1-m) u^{\prime}\left(w^{0}\right)+m u^{\prime}\left(w^{1}\right)\right]} \geq 0
$$


if $\rho^{\prime}(q-r) \geq 0$ and $\pi_{q}(q, r) \geq 0$. Since the first term on the right side of [18] is strictly greater than zero and the second term is weakly greater than zero, $\pi^{c}>\pi(q, r)$. The proof is complete.

The first part of the proposition suggests that if the goal is to induce the firm's compliance, then choosing a monitoring strategy that depends on indirect information about the firm's emissions or the firm's report of its emissions has no value. Moreover, although one might think that the monitoring necessary to induce compliance would be less if the firm's manager is risk averse, this is not so. Likewise a strictly convex penalty for evaded taxes is not useful.

However, the second and third parts of the proposition suggest that there are circumstances under which monitoring effort can be reduced, but only if a regulator implements an enforcement strategy that motivates the firm to evade a portion of its tax liability,

The second part of the proposition covers the case of a risk neutral firm. In this case noncompliance by the firm can be used to reduce monitoring effort if the regulator can make its monitoring strategy a strictly increasing function of the firm's emissions. ${ }^{3}$ Of course, a monitoring strategy cannot be based on a firm's actual emissions, only on observable correlates of its emissions. When such correlates are not available, it is still possible to use a risk neutral firm's noncompliance to reduce monitoring effort if the probability of sanctioning the firm is strictly increasing in its violation. ${ }^{4}$ When a regulator cannot base its monitoring strategy on correlates of a risk neutral firm's emissions and the probability of sanctioning the firm is

\footnotetext{
${ }^{3}$ Stranlund et al. (2009) demonstrated this result; i.e., result (2)(ii) of the Proposition. The new results of the Proposition are those that concern risk aversion and uncertain sanctions; i.e., results (1), (2)(i), and (3) of the Proposition.

${ }^{4}$ Recall that imperfect sanctioning of noncompliant firms is costly because it weakens the deterrence of monitoring and sanctions. This cost is not eliminated by motivating firms' compliance, but it can be eliminated by designing policies that include automatic sanctions for discovered violations. Our results suggest that if this is done, then regulators lose one avenue for using noncompliance to reduce monitoring effort.
} 
independent of its violation, a regulator can do no better than to choose a tax/enforcement strategy that induces the firm's compliance with a constant expected marginal penalty.

However, the third part of the proposition suggests that a regulator does not need a correlate of the firm's emissions or an increasing likelihood of sanctioning the firm if its manager is risk averse. As long as monitoring is a non-decreasing function of the firm's emissions and the probability of sanctioning the firm is non-decreasing in its violation, the regulator can reduce monitoring effort by designing a policy that motivates firms with risk averse managers to be noncompliant.

\section{Should we design emissions tax policies so that firms are noncompliant?}

While these results suggest that there are circumstances under which a regulator can use firms' noncompliance to reduce monitoring effort, they do not suggest that it is optimal to do so. An important cost of allowing firms to be noncompliant is the cost of sanctioning them. As noted in the introduction, most authors in the related literature assume that sanctioning violators is costless. This is obviously a simplifying assumption that does not hold in reality. In fact, punishing noncompliant firms may involve significant costs, including the costs of generating sufficient evidence to convince a court to impose a sanction. Accused firms may also challenge any sanction, and the government may respond with its own efforts to confront these challenges. Designing a tax/enforcement policy that motivates firms to be compliant eliminates the costs of these battles.

Moreover, regulators face significantly more uncertainty when they design policies that lead to noncompliance. While uncertainty by itself need not imply inefficiency, for various reasons real regulators may desire greater certainty in policy outcomes and the public resources 
that are needed to implement a policy. ${ }^{5}$ Under real circumstances, regulators are always uncertain about the parameters of firms’ gross profit functions and the risk preferences of firms’ managers. In designing a tax enforcement policy, this uncertainty means that a regulator can never be certain of the level of emissions each firm chooses. This is true whether the policy induces full compliance or not. However, when a policy is designed to allow noncompliance, uncertainty about firms' profit functions and the risk preferences of their managers implies that regulators will be uncertain about their compliance choices as well. In turn, uncertainty about compliance choices implies ex ante uncertainty about the costs of sanctioning firms. Moreover, if a regulator is able to condition its monitoring effort on correlates of firms' emissions, it will also be uncertain about the monitoring effort it will have to expend. Thus, when policies are designed to allow noncompliance there will be a significant amount of uncertainty about firms’ compliance choices, which in turn produces uncertainty in enforcement costs.

This uncertainty about compliance choices, sanctioning costs, and the required monitoring probabilities is eliminated when tax policies are designed to eliminate noncompliance with a constant expected marginal penalty. This is true because information about firms’ profit functions and the risk preferences of their managers have no bearing on what is required to induce full compliance. It is possible that regulators face uncertainty about the costs of establishing a monitoring probability for firms, but the required monitoring probability is certain. Except for the possibility of ex ante uncertain monitoring costs, there are no other sources of uncertainty in enforcement costs when a regulator enforces an emission tax so that firms are compliant.

\footnotetext{
${ }^{5}$ For example, risk averse bureaucrats and politicians will desire greater certainty about outcomes and public expenditures.
} 
Thus, the choice of whether to design emissions tax policies that motivate firms' compliance or not comes down to this: There are limited circumstances under which policy designers can conserve monitoring effort by implementing policies that they anticipate will result in firms' noncompliance. Under these circumstances the choice of whether to implement an emission tax that results in their noncompliance depends on the tradeoff between lower monitoring costs and the costs of sanctioning noncompliant firms, as well as the regulatory view of the additional uncertainty that is produced by imperfect compliance. It is clear that this determination must be made on a case-by case basis.

It is also clear that implementing an emissions tax that firms evade is more complicated. It is far easier to implement a tax with an enforcement strategy that motivates full compliance. There is a very good chance that doing so would be efficient as well, given the very limited opportunities for using noncompliance to reduce enforcement costs. 


\section{References}

Arguedas, Carmen. 2008. "To Comply or Not To Comply? Pollution Standard Setting under Costly Monitoring and Sanctioning.” Environmental and Resource Economics 41(2), 155-168.

Cremer, Helmuth and Firouz Gahvari. 2002. "Imperfect Observability of Emissions and SecondBest Emission and Output Taxes.” Journal of Public Economics 85(3), 385-407.

Harford, Jon. 1987. "Self-Reporting of Pollution and the Firm's Behavior Under Imperfectly Enforceable Regulations.” Journal of Environmental Economics and Management 14(3), 293303.

Harford, Jon. 1978. "Firm Behavior Under Imperfectly Enforceable Pollution Standards and Taxes.” Journal of Environmental Economics and Management 5(1), 26-43.

Keeler, Andrew. 1991. "Noncompliant Firms in Transferable Discharge Permit Markets: Some Extensions.” Journal of Environmental Economics and Management 21(2), 180-189.

Macho-Stadler, Ines and David Perez-Castrillo. 2006. “Optimal Enforcement Policy and Firm’s Emissions and Compliance with Environmental Taxes.” Journal of Environmental Economics and Management 51(1), 110-131.

Malik, Arun S. 1990. "Markets for Pollution Control when Firms are Noncompliant.” Journal of Environmental Economics and Management 18(2), 97-106.

Montero, Juan-Pablo. 2002. "Prices versus Quantities with Incomplete Enforcement.” Journal of Public Economics 85(3), 435-454.

Sandmo, Agnar. 2002. "Efficient Environmental Policy with Imperfect Compliance.” Environmental and Resource Economics 23(1), 85-103.

Stranlund, John K. and Kanwalroop K. Dhanda. 1999. "Endogenous Monitoring and Enforcement of a Transferable Emissions Permit System.” Journal of Environmental Economics and Management 38(3), 267-282.

Stranlund, John K. 2007. "The Regulatory Choice of Noncompliance in Emissions Trading Programs.” Environmental and Resource Economics 38(1), 99-117.

Stranlund, John K.; Carlos A. Chavez, and Mauricio G. Villena. 2009. "The Optimal Pricing of Pollution When Enforcement is Costly.” Journal of Environmental Economics and Management 58(2), 183-191.

van Egteren, Henry and Marian Weber. 1996. "Marketable Permits, Market Power, and Cheating.” Journal of Environmental Economics and Management 30(2), 161-173. 